\title{
A RETROSPECTIVE DESCRIPTIVE STUDY OF ALUMINIUM PHOSPHIDE POISONING IN A TERTIARY CARE CENTRE OF CENTRAL INDIA
}

\author{
Aneeta Datey1, Ashima Datey Chakrabarty², Abhishek Agarwal ${ }^{3}$ \\ 1 Professor and HOD, Department of Medicine, Amaltas Hospital and Medical College, Dewas, Madhya Pradesh. \\ ${ }^{2}$ Consulting Physician, Indore, Madhya Pradesh. \\ ${ }^{3}$ Consulting Physician, Indore, Madhya Pradesh.
}

\section{BACKGROUND}

ABSTRACT

Poisonings due to metal phosphides in general and Aluminium phosphide (ALP) in particular are a global public health problem. Aluminium phosphide is an inorganic phosphide that has been in use since 1940 as an insecticide and rodenticide for domestic grain preservation and in grain processing facilities. After coming in contact with water, moisture or hydrochloric acid in the stomach, ALP liberates highly toxic phosphine gas $\left.\mathrm{(PH}_{3}\right)$ which produces widespread organ toxicity primarily involving the lungs, heart, liver and kidneys. In India, Aluminium phosphide is widely available as there is no restriction on its sale, that is why it is a common suicidal poison. The past four decades have witnessed high rates of mortality (37\% to $100 \%$ in various studies) with ALP poisoning.

Aims and Objectives- To study the clinical profile and treatment outcomes of ALP poisoning in a tertiary care centre of central India.
\end{abstract}

\section{MATERIALS AND METHODS}

This is a retrospective descriptive study of patients of Aluminium phosphide poisonings, in which their clinical profile and outcome of management was studied. The five-year study period was from Jan 2009 to Dec 2013.

\section{RESULTS}

Aluminium phosphide is a commonly used insecticide for suicidal poisonings. Aluminium phosphide is easily available, as it is a commonly used insecticide and rodenticide in wheat producing areas of central India. A total of 68 patients of aluminium phosphide poisoning were studied in the study period of five years. Ninety four percent patients between the age group of $15-30$ years represented young age group. The intent of poisoning in all the cases was suicidal. There was no correlation between mortality and age or sex.

\section{CONCLUSION}

Aluminium phosphide poisoning is a common lethal insecticide poisoning. Easy availability and lack of control on its sales makes it a common suicidal poison. As an effective antidote is still not available, the treatment mainly remains supportive only. Stricter governmental control on its distribution and sale can help in reducing the mortality due to Aluminium phosphide poisonings. Larger controlled trials are required for comparative evaluation of various methods of management and to assess their outcome.

\section{KEY WORDS}

Aluminium Phosphide, Coconut Oil, Sodium Bicarbonate, Phosphine, Potassium Permanganate.

HOW TO CITE THIS ARTICLE: Datey A, Chakrabarty AD, Agarwal A. A retrospective descriptive study of aluminium phosphide poisoning in a tertiary care centre of Central India. J. Evolution Med. Dent. Sci. 2018;7(21):2584-2587, D0I: $10.14260 /$ jemds/2018/582

\section{BACKGROUND}

Poisonings due to metal phosphides in general and Aluminium phosphide (ALP) in particular are global public health problems. Aluminium phosphide is widely used as an effective grain fumigant and rodenticide in developing countries.[1] It is available in a number of formulations such as tablets, pellets, granules or dust. Commercially, it is available as green, brown or dark grey tablets of 3.0 g each, consisting of aluminium phosphide (56\%) and carbamate (44\%) in the names of Celphos, Alphos, Quickphos, Phosfume, Phostoxin, Talunex, Degesch, Synfume, Chemfume, Phostek or Delicia.[2]

'Financial or Other Competing Interest': None.

Submission 28-03-2018, Peer Review 05-05-2018,

Acceptance 12-05-2018, Published 21-05-2018.

Corresponding Author:

Dr. Ashima Datey Chakrabarty,

Manushri, 43 Chikitask Nagar,

Opp. Bombay Hospital, Indore-452010,

Madhya Pradesh.

E-mail: ashima_aries@yahoo.com

DOI: $10.14260 /$ jemds $/ 2018 / 582$
The most common brand in and around Indore is Celphos. In the UK, Aluminium phosphide is available in the form of tablets or pellets (Phostoxin, Talunex, Degesch) used as rodenticide and the supply is restricted under the pesticide act of 1998 to only the qualified and registered users. In India, Aluminium phosphide is cheap and widely available and is responsible for many cases of poisoning. Aluminium phosphide is known as a suicide poison that can easily be bought and has no effective antidote. Acute aluminium poisoning is a significant under-reported problem throughout the world, particularly in the Indian subcontinent. Every year, about 300,000 people worldwide die because of pesticide poisoning and self-poisoning accounts for one-third of the world's total suicide rate. The most common pesticide agents are organophosphates and various phosphides with ALP being particularly common.[3] In the recent years, the standard of living has improved tremendously in the developing countries due to rapid economic growth. Younger generation has very high expectations in life. Failures in achievements of unrealistic goals by young individuals lead to extreme frustration, which leads to extreme steps of ending the life. The common causative factors which lead to self- 
poisoning were marital disharmony, economic hardships, scolding/ disagreement/ disputes with other family members. The nature of poison makes it a potential agent for chemical terrorists and release of phosphine gas in an enclosed space would lead to respiratory toxicity, public chaos and widespread contamination. Phosphides are highly toxic substances. After coming in contact with water, moisture or the gastric hydrochloric acid, Aluminium phosphide liberates highly toxic phosphine gas $\left(\mathrm{PH}_{3}\right)$ which is the active pesticide compound of Aluminium phosphide. Phosphine is rapidly absorbed in the body by inhalation, ingestion and skin or mucosal contacts. ${ }^{[4]}$ Although, the exact mechanism is not well defined it has been demonstrated that phosphine like cyanide inhibits mitochondrial cytochrome oxidase and reduces cellular oxygen utilisation.[5] Toxicity of phosphine gas is related to oxidant free radicals and associated inhibition of enzymes of metabolism, such as cytochrome oxidase. A characteristic feature of aluminium phosphide poisoning is myocardial suppression and resistant hypotension. The detrimental effects of phosphine gas primarily induce severe gastrointestinal irritation, cardiovascular collapse, acute neuropsychiatric disorders, respiratory and renal failure, and late hepatic damage. After ingestion, toxic features usually develop within a few minutes. The major lethal consequence of aluminium phosphide poisoning is profound circulatory collapse and is secondary to toxins generated, which lead to direct effect on cardiomyocytes, fluid loss and renal damage. The signs and symptoms are non-specific, dose dependent and evolve with the time passing. The dominant clinical feature is severe hypotension refractory to vasopressors. Other features may include dizziness, fatigue, tightness in chest, headache, nausea, vomiting, diarrhoea, ataxia, numbness, paraesthesia, tremors, muscle weakness and diplopia. Death usually occurs within 4 days. Diagnosis of phosphine/ phosphide poisoning is normally based on the history and clinical manifestations.[6] As there are no definitive treatment guidelines, management of this dreadful condition is primarily supportive. Early arrival and prompt attempt to decrease the exposure to poison by gastric lavage with dilute solution of potassium permanganate, coconut oil and/ or sodium bicarbonate, intensive monitoring and supportive therapy have been reported to result in better outcomes. We conducted this retrospective study with an aim to study the outcomes with the various treatment modalities offered at our institute.

\section{MATERIALS AND METHODS}

\section{Methodology}

It is a retrospective descriptive study from January 2009 to December 2013. The study was carried out by retrieving the records of all the consecutive victims of Aluminium Phosphide poisoning who were admitted in the study period. A total of 68 cases of Aluminium phosphide poisoning were admitted in the Intensive Care Unit (ICU) of a tertiary care centre at Indore, Madhya Pradesh.

The provisional diagnosis of Aluminium phosphide poisoning was made on the basis of history of ingestion of Celphos tablets given by patients or their attendants irrespective of symptomatology and/ or by typical odour of Aluminium phosphide at admission when no history of ingestion was available. All patients who came with aluminium phosphide poisoning were included in the study.
All the patients had undergone meticulous examination and were subjected to laboratory investigations as per the hospital protocol. The study and the data of consecutively studied patients was entered on a master chart. The tabulated data was further evaluated and analysed statistically. Statistical analysis was done by Chi-square test and averages. SPSS (Version 20) was used for the statistical analysis. At no stage of this study, the identity of an individual victim was disclosed.

A total of 68 patients of ALP poisoning, presenting to the accident and emergency department of the hospital over a five-year period from January 2009 to December 2013 were reviewed retrospectively. Diagnosis was made by three clinical criteria.

1. Solely on the basis of history given by patients or their attendants, or

2. Symptoms at admission, and/or

3. Typical odour of Aluminium phosphide.

\section{Clinical Assessment}

A detailed history was taken from the patient or his/her family members about the substance ingested, the likely date of manufacture of the substance, time elapsed since ingestion and history of any pre-existing disease. All patients were admitted in the intensive care unit (ICU) after initial resuscitation and gastric lavage with diluted potassium permanganate solution, coconut oil and/ or sodium bicarbonate.

The investigations included a baseline electrocardiogram and biochemical and haematological investigations within an hour of admission in the hospital. Wherever indicated various inotropic agents (Dopamine, noradrenaline and/ or dobutamine) were initiated to stabilise the patient haemodynamically. Patients with respiratory distress were intubated with appropriate size cuffed endotracheal tube and put on mechanical ventilatory support. The severity of the poisoning was assessed from the extent of organ dysfunction (renal, hepatic, neurological, gastrointestinal, cardiovascular, etc.), the need for mechanical ventilation and the requirement of drugs for inotropic support. An intravenous access through internal jugular vein was established for central venous pressure monitoring as well as for guiding the fluid therapy in patients who had presented with cardiovascular instability and respiratory distress. Symptomatic treatment was initiated on a patient-to-patient basis.

\section{Statistical Analysis}

The quantitative variables were presented in terms of Mean (SD) and the qualitative variables were presented as numbers (proportions). Comparisons between survived and not survived groups were made by unpaired t-test for quantitative data. Chi-square test and averages were used for analysis of the data. This statistical analysis was carried out using statistical package for the social sciences (SPSS-Version 20).

\section{Observations}

Table 1 shows the survival in the patients distributed as per the type of gastric lavage and administration of sodabicarb. 
Table 2 shows Complications and laboratory parameters.

\begin{tabular}{|c|c|c|c|}
\hline & Survived & Not Survived & P value \\
\hline Age (years) & $28.17 \pm 6.81$ & $28.33 \pm 9.06$ & \\
\hline \multicolumn{4}{|l|}{ Sex } \\
\hline Male & 20 & 18 & \multirow{2}{*}{0.146} \\
\hline Female & 21 & 9 & \\
\hline \multicolumn{4}{|c|}{ Sodium Bicarbonate $\left(\mathrm{NaHCO}_{3}\right)$} \\
\hline Given & 7 & 0 & \multirow{2}{*}{0.023} \\
\hline Not Given & 34 & 27 & \\
\hline \multicolumn{4}{|c|}{ Potassium Permanganate (KMn04) } \\
\hline Given & 11 & 12 & \multirow{2}{*}{0.133} \\
\hline Not Given & 30 & 15 & \\
\hline \multicolumn{4}{|l|}{ Coconut Oil } \\
\hline Given & 7 & 3 & \multirow{2}{*}{0.497} \\
\hline Not Given & 34 & 24 & \\
\hline \multicolumn{4}{|c|}{ Magnesium Sulphate (MgSO4) } \\
\hline Given & 33 & 24 & \multirow{2}{*}{0.357} \\
\hline Not Given & 8 & 3 & \\
\hline
\end{tabular}

\begin{tabular}{|c|c|c|c|}
\hline Parameters & Survived & Not Survived & P value \\
\hline $\begin{array}{c}\text { Haemoglobin } \\
\text { (gm\%) }\end{array}$ & $12.094 \pm 2.2$ & $13.3 \pm 1.9$ & 0.027 \\
\hline Haematocrit (\%) & $37.5 \pm 6.4$ & $40.64 \pm 5.9$ & 0.037 \\
\hline $\begin{array}{c}\text { Total Leucocytes } \\
\text { (thousand/cu mm) }\end{array}$ & $\begin{array}{c}10373 \pm \\
5969\end{array}$ & $12634 \pm 5388$ & 0.063 \\
\hline $\begin{array}{c}\text { Platelet } \\
\text { (lakh/cumm) }\end{array}$ & $2.76 \pm 0.92$ & $2.35 \pm 1.21$ & 0.164 \\
\hline AST (mg/dL) & $34.09 \pm 399.6$ & $31.12 \pm 1529.59$ & 0.600 \\
\hline ALT (mg/dL) & $37.12 \pm 44.93$ & $142.4 \pm 438.3$ & 0.606 \\
\hline $\begin{array}{c}\text { Total Bilirubin } \\
\text { (mg/dL) }\end{array}$ & $0.70 \pm 0.32$ & $1.05 \pm 0.594$ & 0.020 \\
\hline $\begin{array}{c}\text { Direct Bilirubin } \\
\text { (mg/dL) }\end{array}$ & $0.32 \pm 0.164$ & $0.48 \pm 0.45$ & 0.321 \\
\hline $\begin{array}{c}\text { Indirect Bilirubin } \\
\text { (mg/dL) }\end{array}$ & $0.42 \pm 0.285$ & $0.64 \pm 0.41$ & 0.017 \\
\hline $\begin{array}{c}\text { INR } \\
\text { Urea (mg/dL) }\end{array}$ & $26.40 \pm 0.83 \pm 9.13$ & $1.23 \pm 0.23$ & 0.603 \\
\hline Creatinine (mg/dL) & $1.0020 \pm 0.59$ & $1.49 \pm 1.48$ & 0.003 \\
\hline Sodium (mmol/L) & $140.6 \pm 4.6$ & $140.95 \pm 5.0$ & 0.787 \\
\hline $\begin{array}{c}\text { Potassium } \\
\text { (mmol/L) }\end{array}$ & $4.070 \pm 0.565$ & $4.17 \pm 0.924$ & 0.720 \\
\hline Chloride (mmol/L) & $103.53 \pm 5.0$ & $97.6 \pm 20.53$ & 0.173 \\
\hline Table 2. Complications and Laboratory Parameters \\
\hline
\end{tabular}

\section{RESULTS}

94\% of the admitted patients belonged to the young age group (15 - 30 years). Majority of the patients were male (55.5\%). The intent was suicidal in all cases. Nausea and vomiting were the most common symptoms at the time of admission in the hospital. Abdominal pain was complained by majority of patients $(80 \%)$. Anxiety and palpitations were present in $42(61.72 \%)$ and $16(23.5 \%)$ patients respectively. Out of 68 patients, 27 patients died during the course of admission.

Table 1 shows that there was no correlation of mortality with age and sex of patients. Ninety one percent (62) patients were admitted within six hours of aluminium phosphide ingestion and only six patients were brought after 6 hours of ingestion, out which three died due to cardiogenic shock.

Cause of death was ARDS alone in 1 case, whereas cardiogenic shock alone was the cause of death in 10 (37.0\%) cases. Both ARDS and Shock was present in 16 (59.3\%) cases.
Gastric lavage was done using diluted potassium permanganate, coconut oil, magnesium sulphate and sodium bicarbonate was given as primary treatment support in 23 , 10, 57 and 7 patients respectively. No mortality occurred in all the 7 patients receiving $\mathrm{NaHCO} 3(\mathrm{p}=0.023)$.

Survival was seen in those patients who had consumed outdated tablets as evidenced by the change in the colour of the tablets and the date of manufacture printed on the bottles.

The limitation of our study was that it was retrospectively designed. Hence, larger prospective studies need to be done in the future to find the variables at admission namely the need for mechanical ventilation, hypotension at admission requiring vasoactive drugs, low $\mathrm{pH}$ values, low serum bicarbonate levels, low serum creatinine levels and low APACHE II scores which could be used to detect patients at greater risk of mortality from acute ALP.

\section{DISCUSSION}

This retrospective descriptive study included all the patients of aluminium phosphide poisonings who were admitted over a period of five years from January 2009 to December 2013. The patients were received by the hospital after different time intervals following the consumption of the lethal rodenticide and hence the outcome could not be compared between the various patient groups and treatment methods. Aluminium phosphide is a commonly used suicidal poison due to its easy availability. Government has not laid down any regulatory act for its usage. Mortality due to the suicidal poisonings by consumption of aluminium phosphide can only be reduced by reducing the number of incidents, as no effective antidote is available. Larger controlled trials on various agents used in the treatment can set a standard protocol.

\section{CONCLUSION}

Our study was a retrospective collection of data and its interpretation. The various methods used in the management could not be comparatively evaluated for their outcome, as the number of patients is small, and the various patients of poisoning reached the hospital after incomparable intervals following the consumption of the poison. Larger multicentric controlled trials are required to formulate effective protocols for the management of aluminium phosphide poisoning. Strict governmental control on distribution and sale of this lethal poison will go a long way in reducing the mortality due to aluminium phosphide poisonings.

\section{REFERENCES}

[1] Bumbrah GS, Krishan K, Kanchan T, et al. Phosphide poisoning: a review of literature. Forensic Sci Int 2012;214(1-3):1-6.

[2] Gurjar M, Baronia AK, Azim A, et al. Managing aluminum phosphide poisonings. J Emerg Trauma Shock 2011;4(3):378-84.

[3] Mehrpour 0, Jafarzadeh M, Abdollahi M. A systematic review of aluminium phosphide poisoning. Arh Hig Rada Toksikol 2012;63(1):61-73.

[4] Kariman H, Heydari K, Fakhri M, et al. Aluminium phosphide poisoning and oxidative stress: serum biomarker assessment. J Med Toxicol 2012;8(3): 281-4. 


\section{Jemds.com}

[5] Moghadamnia AA. An update on toxicology of aluminium phosphide. Daru 2012;20(1):25.
Original Research Article

[6] Shadnia S, Sasanian G, Allami P, et al. A retrospective 7-years study of aluminum phosphide poisoning in Tehran: opportunities for prevention. Hum Exp Toxicol 2009;28(4):209-13. 